\title{
Overlapping Plant Signal Transduction Pathways Induced by a Parasitic Nematode and a Rhizobial Endosymbiont
}

\author{
Hinanit Koltai, ${ }^{1}$ Murali Dhandaydham, ${ }^{1}$ Charles Opperman, ${ }^{1}$ Judith Thomas, ${ }^{2}$ and David Bird ${ }^{1}$ \\ ${ }^{1}$ Department of Plant Pathology, and ${ }^{2}$ Phytotron, North Carolina State University, Raleigh 27695, U.S.A. \\ Submitted 12 October 2000; Accepted 9 July 2001.
}

\begin{abstract}
Root-knot nematodes and rhizobia establish interactions with roots characterized by the de novo induction of host structures, termed giant cells and nodules, respectively. Two transcription regulators, $P H A N$ and $K N O X$, required for the establishment of meristems were previously shown to be expressed in tomato giant cells. We isolated the orthologues of PHAN and KNOX (Mt-phan and Mt-knox-1) from the model legume Medicago truncatula, and established the spatial distribution of their expression in situ. We confirmed that Mt-phan and Mt-knox-1 are expressed in lateral root initials and in nematode-induced giant cells and showed that they are expressed in nodules induced by Sinorhizobium meliloti. Expression of both genes becomes spatially restricted as the nodules develop. We further examined nematode feeding sites for the expression of two genes involved in nodule formation, $\operatorname{ccs} 52$ (encodes a mitotic inhibitor) and ENOD40 (encodes an early, nodulation mitogen), and found transcripts of both genes to be present in and around giant cells induced in Medicago. Collectively, these results reveal common elements of host responses to mutualistic and parasitic plant endosymbionts and imply that overlapping regulatory pathways lead to giant cells and nodules. We discuss these pathways in the context of phytohormones and parallels between beneficial symbiosis and disease.
\end{abstract}

Additional keywords: cytokinin, Meloidogyne incognita, Nod factor, PHANTASTICA, polar auxin flow, rough sheath2.

Plants interact with a wide range of organisms in the rhizosphere, leading to various mutualistic and pathological associations. Amongst the most elaborate and intimate interactions are those that occur between root-knot nematodes (Meloidogyne spp.) and their many hosts and those associated with the induction of nitrogen-fixing nodules on legumes by rhizobial bacteria. In both cases, host cells are directed by the invading organism to initiate the cell cycle and to form a complex and novel structure; and although one is detrimental to the host (nematode) and the other beneficial (rhizobia), both can, in the

Corresponding author: David Bird;

Address: Box 7616, NCSU, Raleigh, NC 27695, U.S.A.;

Telephone: +1-919-515-6813; Fax: +1-919-515-9500;

E-mail: david_bird@ncsu.edu

Nucleotide sequence data can be found at the GenBank data base at accession nos. AF308453 and AF308454. broadest sense, be considered symbiotic interactions (Bird 1975; Parniske 2000).

Under conditions of nitrogen limitation, rhizobia specify the induction of a new meristem from which cells ultimately differentiate into the characteristic and complex multicelled organ termed a nodule. Initially, cells within the root cortex divide and form a nodule primordium. In indeterminate nodules, a persistent apical meristem develops, from which cells continuously exit to enter the nodule differentiation program by division arrest, followed by several rounds of endoreduplication and increase in cell size. These enlarged and polyploid cells are invaded by, and ultimately host, the bacteroids, which are the nitrogen-fixing form of rhizobia (Schultze and Kondorosi 1998). In contrast, the feeding sites induced by root-knot nematodes are characterized by the formation of discrete multinucleate cells, termed giant cells, that form in the absence of cell division (Bird and Koltai 2000; Williamson and Hussey 1996). Parenchyma cells in the vascular cylinder expand to become giant cells early in the parasitic association. They undergo rounds of mitosis uncoupled from cytokinesis, becoming highly polyploid, and their cell wall and cytoplasm content are altered. In many but not all hosts, cortical and pericycle cells around the giant cells expand and divide, resulting in the formation of a gall.

The cytology of giant cells and nodules has been well documented, but yet neither the presumed receptors for the inductive signal nor the components of the ensuant signal transduction pathway are understood for either. In contrast, the molecule named Nod factor, which is necessary and, in certain plant species (Truchet et al. 1991), sufficient for the primary induction of nodules, has been identified and subjected to extensive analysis (Dénarié et al. 1996). The identity and structure of Nod factor was originally established by a thorough and comprehensive genetic analysis of the rhizobial bacteria that produce it (Lerouge et al. 1990); because most of the agriculturally important Meloidogyne spp. reproduce asexually, a similar strategy is not feasible for identifying candidate, nematode-encoded inducers of giant cells. As an alternative, we chose to study gene expression in giant cells and isolated and sequenced several hundred cDNA clones from tomato giant cells (Bird 1996; Bird and Wilson 1994); these are available from GenBank. Included in this set is Le-phan (Thierry et al. 1999), which is the canonical member of a family of plant Myb transcription regulators called PHANTASTICA (PHAN) in Antirrhinum majus 
(Waites et al. 1998) and rough sheath2 ( $r s 2)$ in maize (Timmermans et al. 1999; Tsiantis et al. 1999b). Genetic studies revealed that PHAN/rs 2 is required for normal meristem function (Timmermans et al. 1999; Tsiantis et al. 1999b; Waites et al. 1998). Class I knotted (KNOX) genes also are required for normal meristem maintenance and function, and KNOX mutations phenocopy certain PHAN alleles (Schneeberger et al. 1998). Importantly, KNOX expression has been linked to the regulation of polar auxin flow (Tsiantis et al. 1999a), and a strict correlation was observed between elevated cytokinin levels and KNOX expression. This result suggests either that cytokinins may regulate $K N O X$ expression or are a secondary signal regulated by KNOX (Frugis et al. 1999; Rupp et al. 1999). Hence, $K N O X$ (and perhaps $P H A N$ ) might represent a link between phytohormones and transcriptional responses in meristems.

Based on genetic experiments in maize (Schneeberger et al. 1998; Timmermans et al. 1999; Tsiantis et al. 1999b) and snapdragon (Waites et al. 1998), it was proposed that PHAN functions as a repressor of $K N O X$. However, this appears not to be the case in tomato, where in situ localization studies established that expression of the Tkn2 KNOX gene is coincidental with that of Le-phan, implying that Le-phan alone is insufficient for KNOX repression (Koltai and Bird 2000a). Further, it was shown in tomato that KNOX and Le-phan are coinduced in Meloidogyne-specified giant cells and are coexpressed in primary root and lateral root meristems (Koltai and Bird 2000a).

Thus, in tomato, it seems that KNOX and Le-phan expression might be a general feature of meristems and also that nematode-induced giant cells share at least some of the transcriptional characteristics of true meristems. We wished to establish these patterns in another compound-leaf plant and also to determine if PHAN and KNOX expression accompanies the de novo induction of other types of meristem, such as those induced by rhizobia; we chose the model legume Medicago truncatula (Cook 1999) in which to address these questions.

Using the Medicago orthologues of Le-phan and Tkn2, we established the temporal and spatial distribution of their expression in situ (Koltai and Bird 2000b) in developing root organs, thereby confirming our findings from tomato. We examined PHAN and KNOX expression during root-knot nematode and rhizobium endosymbioses and found expression of both genes in each case, suggesting that the types of meristem induced by these distinct organisms in their host might employ overlapping signal transduction pathways. To further explore this possibility, we examined nematode feeding sites for the expression of two genes previously shown to be important for nodule function. One of these genes, $\operatorname{css} 52$, encodes a mitotic inhibitor (Cebolla et al. 1999), and the other, ENOD40, is an early, mitogenic nodulation gene essential for nodule formation (Charon et al. 1999; Schultze and Kondorosi 1998). Transcripts of both genes were shown to be present in and around giant cells induced in Medicago. Collectively, these results demonstrate the similarities of host responses to a mutualistic and parasitic plant endosymbiont and imply that overlapping regulatory pathways lead to giant cells and nodules.

\section{RESULTS}

\section{Isolation of M. truncatula PHANTASTICA and class I $K N O X$ genes.}

The Mybs that comprise the PHANTASTICA family have a unique and characteristic tryptophan-to-leucine substitution in a functionally important and conserved position in their DNA sequence-specific recognition motif (Thierry et al. 1999). Thus, the presence of this leucine (Fig. 1A) in the deduced sequence of the M. truncatula Myb we isolated unequivocally establishes this as being the Medicago orthologue of PHANTASTICA, and we named it Mt-phan.

The class I knotted (KNOX) genes encode a family of homeodomain proteins characterized by a highly conserved and functionally important $\alpha$ helix at the center of a larger, but less-well-conserved, KNOX domain (Sakamoto et al. 1999). Although many previous expression studies, particularly those employing antibodies (e.g., Timmermans et al. 1999; Tsiantis et al. 1999b), were not selective for specific KNOX family members, our prior studies in tomato (Koltai and Bird 2000a) were specific for the Tkn2 KNOX gene. Consequently, we isolated the Medicago orthologue of Tkn2, which we named Mtknox-1. As shown in Figure 1B, in addition to its high degree of homology with the tomato Tkn2 protein, KNOX-1 from pea and the tobacco NTH15 protein (Sakamoto et al. 1999), the Mt-knox-1-deduced protein also is highly similar to Arabidopsis SHOOTMERISTEMLESS (STM). The grouping of these genes by sequence similarity is supported by genetic findings in which $T k n 2$ and $S T M$ were demonstrated to play a pivotal role in meristem development and function (Chen et al. 1997; Hareven et al. 1996; Janssen et al. 1998a, 1998b; Long et al. 1996; Parnis et al. 1997).

\section{$P H A N$ and $K N O X$ transcripts colocalize in M. truncatula lateral root meristem and root-knot nematode feeding sites.}

In tomato, expression of Le-phan and the Tkn2 KNOX gene is both spatially and temporally coincidental in meristematic tissue and in young, developing organs, including lateral root primordia (Koltai and Bird 2000a). Using primers for Mt-phan and Mt-knox-1, we found that the same is true in Medicago spp. (Fig. 2A and B). Transcripts from both genes colocalized strongly and specifically to cells of the developing meristem; cytoplasmic staining was undetectable in a no-primer control (Fig. 2C). This result reinforces the notion that these genes are generally expressed in meristems. Thus, as is the case in tomato (Koltai and Bird 2000a) and in contrast to the situation in simple-leaf plants (Timmermans et al. 1999; Tsiantis et al. 1999b; Waites et al. 1998), PHAN and KNOX exhibit a spatially and temporally overlapping expression profile in Medicago.

The canonical PHANTASTICA gene was originally isolated as a tomato expressed sequence tag (EST) that was up-regulated in root-knot nematode-induced giant cells (Bird and Wilson 1994). Tkn2 KNOX was subsequently found also to be expressed at nematode feeding sites in tomato (Koltai and Bird 2000a). Using in situ reverse-transcription-polymerase chain reaction (RT-PCR), we found the same to be true in Medicago; both Mt-phan and Mt-knox-1 are strongly expressed in feeding sites 6 days postinoculation (dpi) with Meloidogyne incognita (Fig. 2D and E). Expression is evident in the giant cells and also in surrounding cells in the vascular cylinder. By contrast, 
neither gene was expressed in mock-inoculated Medicago roots (Fig. 2F).

Spatial and temporal expression of PHAN, KNOX, and $\operatorname{ccs} 52$ in M. truncatula nodules induced by Sinorhizobium meliloti.

Like root-knot nematodes, rhizobia induce reprogramming of host cellular fate. To explore the possibility that Mt-phan and Mt-knox-1 might play a role in the rhizobium-plant interaction, we used in situ RT-PCR to map their expression during nodule formation in Medicago. To provide a precise frame of reference with other published studies, we also established the temporal and spatial profile for $\operatorname{css} 52$. This gene encodes a mitotic inhibitor expressed during indeterminate nodule development (Cebolla et al. 1999) and presumably plays a role in endoreduplication of nodule nuclei.

In nodules induced with $S$. meliloti at $3 \mathrm{dpi}$, Mt-phan and $M t-k n o x-1$ transcripts are readily detected in all cells of the developing nodule primordium (Fig. 3A and B). By 4 to 5 dpi, nodules continue to express both Mt-phan and Mt-knox-1, but expression is restricted to the meristem, the prefixing zone, and a subset of the differentiated, nitrogen-fixing cells (Fig.
3C and D). A little later in nodule development (approximately $6 \mathrm{dpi}$ ), expression of Mt-phan and Mt-knox-1 becomes restricted principally to the meristem, although some expression is evident in the parenchyma (Fig. 3E and F) and the nodule vascular cylinder (data not shown). No cytoplasmic staining for either Mt-phan or for Mt-knox-1 transcripts was evident in the nitrogen-fixing cells or in the senescence zone (Fig. 3E and F). Staining was undetectable in a control RT-PCR in situ in which Taq DNA polymerase was omitted (Fig. 3G). The general anatomy of a $S$. meliloti-induced nodule is evident, and approximate boundaries of the major zones of differentiation recognized in nodules also are indicated. Cells of all zones contain RNA as indicated by an in situ RT-PCR using primers specific for $18 \mathrm{~S}$ rRNA (Fig. $3 \mathrm{H}$ ).

Expression of ccs52 is clearly evident in cells of the nodule primordium (Fig. 3I), but based on staining intensity and color, c cs52 transcript levels become reduced during nodule maturation (Fig. 3J) and increasingly restricted. (Although in situ RTPCR should not be considered quantitative, we suspect that the time necessary for color development and also the final color hue and intensity may be attributed to differences in the

A

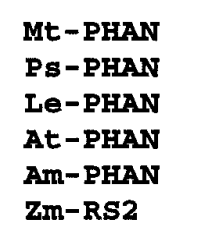

Zm-RS2

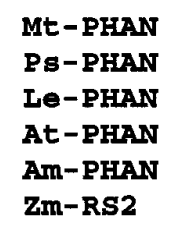

B
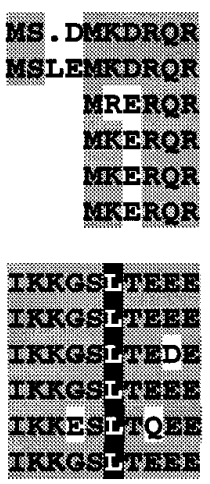

*
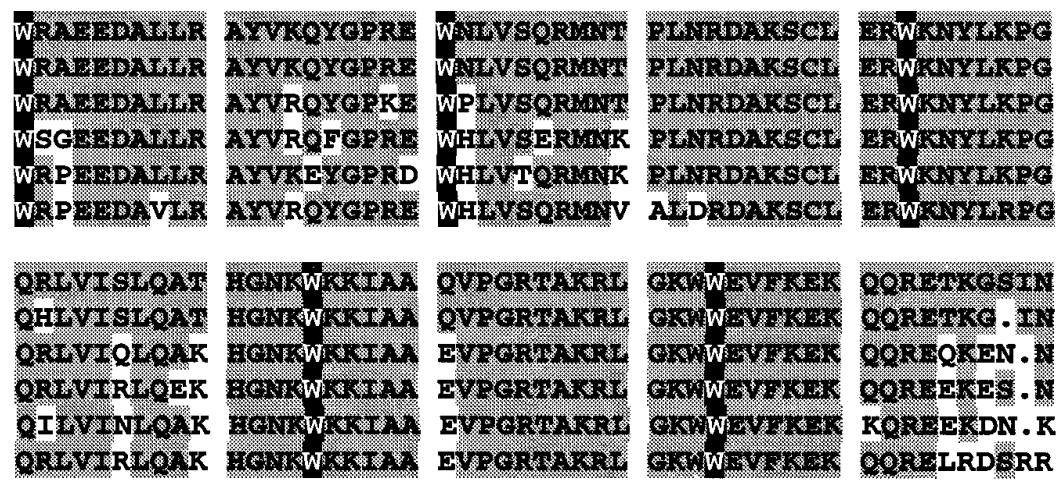

\section{Nt $-\mathrm{NTH} 15$ \\ Le-TKN2 \\ Mt - KNOX1 \\ Ps -KNOX1 \\ At $-\mathbf{S T M}$ \\ Nt - NTH15 \\ Le-TKN2 \\ Mt-KNOX1 \\ Ps-KNOX1 \\ At-STM}
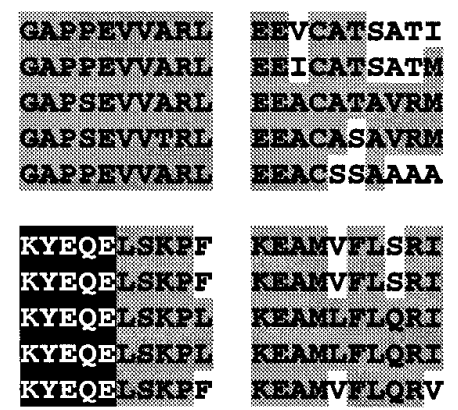

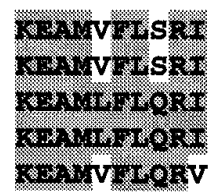

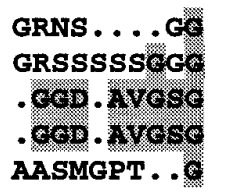

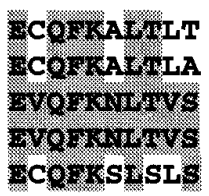

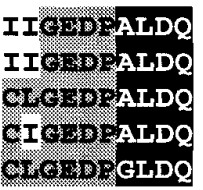

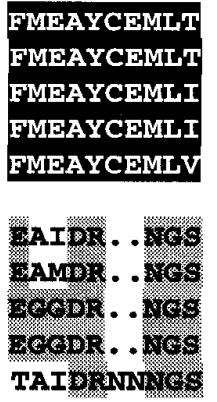

Fig. 1. Medicago truncatula orthologues of PHAN and KNOX. A, Multiple alignment of the deduced amino acid sequence of Mt-phan and other PHAN proteins at the two imperfect amino acid repeats of the DNA sequence-specific recognition motif. Mt-phan amino acids conserved with PHAN proteins are highlighted in gray. The conserved tryptophan residues of the Myb DNA binding domain are highlighted in black, and an asterisk marks the unique and characteristic tryptophan-to-leucine substitution diagnostic of PHAN (Thiery et al. 1999). Mt-PHAN, M. truncatula, accession no. AF308453; PsPHAN, Pisum sativum, accession no. AF299140; Le-PHAN, Lycopersicon esculentum, accession no. AF148934; At-PHAN, Arabidopsis thaliana, accession no. AF175996; Am-PHAN, Antirrhinum majus, accession no. AJ005586; Zm-RS2, and Zea mays rough sheath 2 (the maize orthologue of PHAN), accession no. AF126489. B, Multiple alignment of the deduced sequence of Mt-knox-1 with other KNOX class I proteins at the KNOX domain. Residues conserved between Mt-knox-1 and other KNOX proteins are highlighted in gray. The highly conserved and functionally important $\alpha$-helix domain is highlighted in black (Sakamoto et al. 1999). Nt-NTH15, Nicotiana tabacum, accession no. T01735; Le-TKN2, Lycopersicon esculentum, accession no. AAD00251; Mt-KNOX1, M. truncatula, accession no. AF308454; Ps-KNOX, Pisum sativum, accession no. T06382; and At-STM, Arabidopsis thaliana SHOOTMERISTEMLESS, accession no. Q38874. 
amount of specific mRNA in the cell; brown staining represents lower transcript abundance and purple-black staining reflects higher abundance.) By 6 dpi, ccs52 transcripts are detectable principally in the meristem and prefixing zones (Fig. 3K), with a sharp boundary with the nitrogen-fixing zone. This pattern is in strict accord with that established by Cebolla et al. (1999) for $M$. sativa and further demonstrates that nuclear staining in the nitrogen-fixing zone does not represent specific expression. In contrast, true expression in the nitrogen-fixing cells is demonstrated by the cytoplasmic staining of all cells of the nodule detected for $18 \mathrm{~S}$ ribosomal transcripts (Fig. 3H).

In mature nodules, expression of Mt-phan is principally restricted to the nodule meristem, although some of the nitrogen-fixing cells were stained for PHAN transcripts (Fig. 3L). Mt-phan message also is evident in the nodule cortex, but ap- parently much less abundantly than in the meristem (compare also with the $18 \mathrm{~S}$ rRNA control, Fig. 3N). Mt-knox-1 transcripts are detectable at apparently very low levels in the meristem and in some of the cells of the nitrogen-fixing zone (Fig. $3 \mathrm{M})$. Some staining also was seen around the nodule vascular system (data not shown), but in contrast to those of Mt-phan, Mt-knox- 1 transcripts are clearly absent from the nodule cortex (Fig. 3M). Surprisingly, in mature nodules, ccs52 mRNA appeared slightly more widely distributed than in 6-dpi nodules, being detectable in the cortex, the meristem, and some of the nitrogen-fixing cells (Fig. 3O). This slight difference from the published expression pattern of $\operatorname{ccs} 52$ (Cebolla et al. 1999) may result from developmental-stage differences of the nodules or, alternatively, from the high sensitivity of the in situ RT-PCR detection method (Koltai and Bird 2000b).
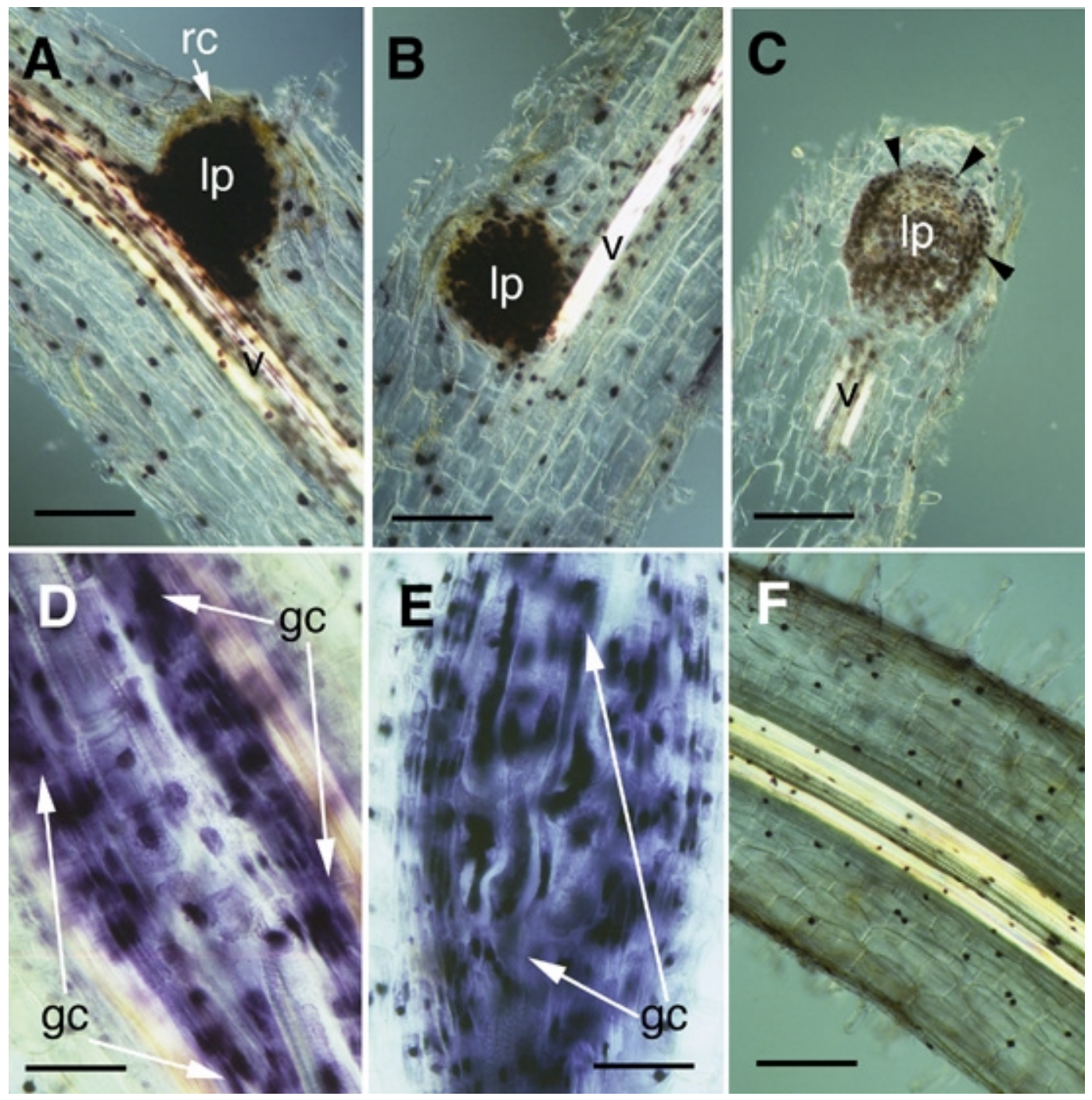

Fig. 2. In situ localization of Mt-phan and Mt-knox-1 transcripts in lateral roots and root-knot nematode-induced feeding sites in Medicago truncatula. A and B, Detection of Mt-phan and Mt-knox- 1 mRNAs, respectively, in book-matched, longitudinal sections of roots in which lateral root primordia (lp) have developed. Dark staining represents detection of Mt-phan and Mt-knox-1 transcripts. C, No-primer control. In this control, the punctate signal (arrowheads) represents nuclear staining only. Root-cap initials (rc) and the vascular cylinder (v) also are indicated. D and E, Detection of Mt-phan and Mt-knox-1 mRNAs, respectively, in longitudinal sections of Medicago roots 6 days postinfection with Meloidogyne incognita larvae. Staining is apparent both in the nematode-induced giant cells ( $\mathrm{gc}$ ) and also in adjacent cells in the vascular cylinder. The ends of individual giant cells are delineated by arrows. F, Staining is clearly absent in mock-inoculated roots, amplified with primers for Mt-phan; a similar result was obtained using Mt-knox-1specific primers (data not shown). Bars $=100 \mu \mathrm{m}$. 
As an additional control, we examined the spatial distribution of Mt-ENOD40 transcripts in 6-dpi nodules. In agreement with the published expression pattern in alfalfa nodules (Asad et al. 1994; Crespi et al. 1994; Fang and Hirsch 1998; Kouchi and Hata 1993), we observed Mt-ENOD40 to be expressed primarily in the meristem and prefixing zones and in cells peripheral to the central region (data not shown).

\section{$E N O D 40$ and $\operatorname{ccs} 52$ are expressed in lateral root primordia and root-knot nematode feeding sites in Medicago.}

Based on gus expression in transgenic alfalfa ( $M$. sativa), ENOD40 has been shown to be expressed in lateral root primordia (Fang and Hirsch 1998), and we confirmed that result in M. truncatula (Fig. 4A). To explore the possibility that the same might be true for other key nodule genes, we examined lateral root primordia for the presence of $M t-c c s 52$ transcripts and found that this gene too is strongly expressed in this tissue (Fig. 4B). Interestingly, whereas Mt-phan and Mt-knox-1 transcripts are restricted to cells of the developing primordium, $M t-E N O D 40$ and $M t$-ccs52 both appear also to be expressed in cells around the vascular cylinder extending acropetal and basopetal from the developing lateral root (Fig. 4A and B), but not in other, nonmeristematic parts of the root (data not shown).

Our findings that ENOD 40 and ccs 52 transcripts are coincidental with Mt-knox-1 and Mt-phan mRNA in lateral root primordia and also in developing nodules led us to ask if ENOD40 and $\operatorname{css} 52$ are expressed in giant cells. In a preliminary study in tomato (A. M. Hirsch and D. M. Bird, unpublished data), ENOD40 transcripts were detected in giant cells by in situ hybridization. Using in situ RT-PCR, we examined developing nematode feeding sites in Medicago, 6 dpi with root-knot nematode, and found that ENOD 40 and $\operatorname{ccs} 52$ both are expressed in giant cells (Fig. 4C and D) and in the cells immediately surrounding the giant cells, which presumably include cells of the developing gall. This pattern strongly recapitulates that observed for Mt-knox-1 and Mt-phan (Fig. $2)$. Even though we have not established an extensive time course of expression of Mt-phan, Mt-knox-1, ENOD40, and $\operatorname{ccs} 52$, it appears they remain expressed at least during the first 2 weeks of giant cell development (data not shown). Interestingly, by 8 weeks postinoculation, when no transcripts could be detected inside the giant cells (including an 18S rRNA control, which might signify that the giant cells were dead), transcripts of these four genes remained detectable around the vascular system (data not shown). By contrast, except in meristems, none of these four genes were expressed in mockinfected roots (Fig. 2F).

\section{DISCUSSION}

We are interested in the parasitic association between rootknot nematode and its host, and we previously proposed a model whereby this interaction is established via the recruitment of pathways in the host that normally are utilized during plant development (Bird 1996). It is increasingly evident that there are recurring themes in the response of plants to invasion by a wide range of endosymbiotic microorganisms (Parniske 2000), presumably reflecting the exploitation of a common or overlapping set of host core components by the invader. To further explore this concept, we compared the induction of host genes by rhizobial bacteria with that of root-knot nematodes. The de novo induction of a persistent apical meristem during formation of indeterminant nitrogen-fixing nodules is a universally accepted feature of the rhizobial-legume symbiosis (Crespi and Gálvez 2000). In contrast, although it has been noted that "the cytoplasms of developing giant cells [induced in host roots by root-knot nematodes] are reminiscent of active meristems" (Huang 1985), they are not widely regarded as being meristems, possibly because they do not divide (Williamson and Hussey 1996). Nevertheless, similarities between nodule and gall formation have been noted (Bird 1996), and here we report results that demonstrate that specific components of host signal transduction cascades are activated in response to these mutualistic and parasitic plant endosymbionts.

We used an in situ approach to establish a temporal and spatial expression map of PHAN and KNOX in Medicago spp. These two genes have been demonstrated by genetic means to be central to the establishment and maintenance of meristems in a range of plants, including Arabidopsis, maize, Antirrhinum majus, and tomato (Goliber et al. 1999; Long et al. 1996; Timmermans et al. 1999; Tsiantis et al. 1999b; Waites et al. 1998), and also shown to be expressed in giant cells

Fig. 3. In situ localization of Mt-phan, Mt-knox-1, and Mt-ccs52 transcripts during nodule development in Medicago truncatula roots inoculated with Sinorhizobium meliloti. A and B, Detection of Mt-phan and Mt-knox-1 mRNAs, respectively, in book-matched, longitudinal sections of a nodule primordium (np), 3 days postinoculation (dpi). All cells of the primordium exhibit dark staining indicative of the presence of specific transcripts. C and D, Detection of Mt-phan and Mt-knox-1 mRNAs, respectively, in book-matched, longitudinal sections of a nodule, 4 to 5 dpi. Dark staining is evident in the meristem (m), the prefixing zone (p), and a subset of the nitrogen-fixing cells (white arrowheads). E and F, Detection of Mt-phan and Mt-knox-1 mRNAs, respectively, in book-matched, longitudinal sections of a nodule, $6 \mathrm{dpi}$. Signal is detected in the cytoplasm of meristem (m) and parenchyma cells (pr), but is absent in nitrogen-fixing cells (nt), although these cells do exhibit nuclear staining (n). Nuclear staining does not represent specific expression (Koltai and Bird 2000b), nor does the tan-colored cytoplasmic pigmentation of the nitrogen-fixing cells. G, This natural pigmentation is readily apparent in the no-Taq control, which also shows an absence of staining in the major zones of the nodule, including meristem (m), prefixing zone (p), nitrogen-fixing zone (nt), the senescence zone (s), parenchyma cells (pr), cortex (c), and the vascular cylinder (v). Contrast this with $\mathbf{H}$, the staining of all cells of a nodule, 4 to $5 \mathrm{dpi}$, using 18 rRNA primers. I, Detection of $M t$ - $\operatorname{css} 52 \mathrm{mRNAs}$ in a longitudinal section of a nodule, 3 dpi. $\mathbf{J}$, Detection of $M t$ $\operatorname{ccs} 52$ mRNAs in a longitudinal section of a nodule, 4 to $5 \mathrm{dpi}$. K, Detection of $M t$-ccs 52 mRNAs in a longitudinal section of a nodule, 6 dpi. Signal is localized primarily to the nodule meristem (m) and the prefixing zone (p); in the nitrogen-fixing zone, only nuclei (n) are stained. L, Detection of $M t$ phan mRNAs in a longitudinal section of a mature nodule. Signal is localized to the nodule meristem (m) and some of the nitrogen-fixing cells (white arrowheads); $\mathrm{n}$, stained nuclei in the cortex (c). M, Detection of Mt-knox-1 mRNAs in a longitudinal section of a mature nodule. A faint signal is apparent in the meristem (m) and in a subset of the nitrogen-fixing cells (white arrowheads). Nuclear staining (n) in the nodule cortex (c) (similar to that in $\mathbf{L}$ ) serves as an internal control for the staining process. N, Detection of $18 \mathrm{~S}$ rRNA in a longitudinal section of a mature nodule. Signal is localized to the nodule meristem (m) and cortex (c) and to some of the nitrogen-fixing cells (white arrowheads). Absence of staining in some cells (*) of this mature nodule suggest that these cells are no longer transcriptionally active. O, Detection of Mt-ccs52 mRNAs in a longitudinal section of a mature nodule. Signal is detected in the nodule meristem $(\mathrm{m})$, cortex $(\mathrm{c})$, and in some of the nitrogen-fixing cells (white arrowheads). Bars $=100 \mu \mathrm{m}$. 

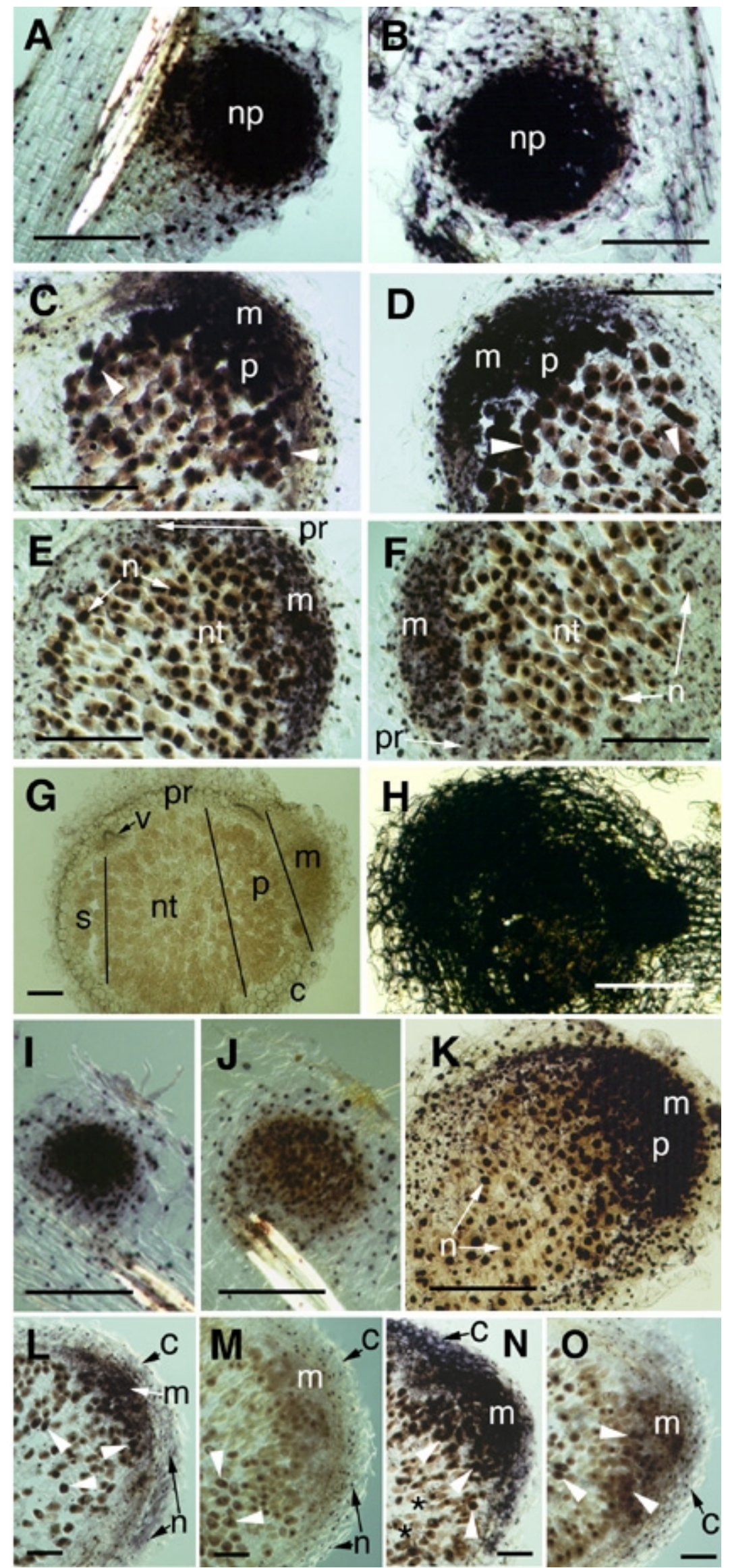
induced by Meloidogyne spp. in tomato (Koltai and Bird 2000a). Here, we show that Mt-phan and Mt-knox-1 are expressed not only in Medicago meristems, but also in nodules and nematode feeding sites. This result reinforces our contention that giant cells exhibit meristematic characteristics (Bird and Koltai 2000; Koltai and Bird 2000a) and implies that overlapping regulatory pathways lead to giant cells and nodules. Importantly, the plant components we identified as being part of the plant response both to rhizobium and to root-knot nematodes are ones that are expressed during programmed plant development. This is consistent with the idea that endosymbionts recruit pathways in the host that normally are utilized during programmed development.

Meloidogyne spp. induce stereotypical giant cells in a broad range of vascular plants, suggesting that the process of giant cell formation involves some fundamental and widely conserved aspect(s) of plant biology. Because of their central role in mediating developmental processes in plants, it has long been speculated that phytohormones may play a role in feeding site formation by root-knot nematodes (Bird and Koltai 2000). Recently, some direct evidence to support this notion has begun to emerge. Using reporter constructs, Hutangura et al. (1999) mapped changes in auxin levels during root-knot nematode feeding site formation and concluded that polar auxin transport was inhibited, possibly mediated through activation of the flavonoid pathway. A similar induction of the flavonoid pathway has been observed in the formation of lateral roots (Pelosi et al. 1995) and in Rhizobium nodules (Mathesius et al. 1998). A distribution of auxin functionally equivalent to that at nematode galls was observed during nodule formation (Mathesius et al. 1998).

During normal plant development, expression of $K N O X$ has been tightly correlated with regulation of polar auxin transport (Tsiantis et al. 1999a) and elevated cytokinin levels (Frugis et al. 1999; Rupp et al. 1999), and we postulate that Mt-knox-1 expression in nodules and in nematode feeding sites is causally involved in regulating phytohormone levels. Our spatial and temporal maps of $K N O X$ expression are consistent with the notion that $K N O X$ might be a key regulator of auxin and perhaps also cytokinin levels (Bird and Koltai 2000). For example, at the onset of nodule differentiation, all cells of the nodule primordia express $K N O X$. Auxin is undetectable in these cells, but as $K N O X$ expression becomes more restricted in the developing nodule, the pattern of auxin expression becomes expanded (Mathesius et al. 1998). At nematode feeding sites, auxin accumulated basipetal and was reduced acropetal to the forming gall (Hutangura et al. 1999); at this time, $K N O X$ is expressed in giant cells and also to some extent in developing galls. It has previously been suggested that Nod factor impinges on a cytokinin signal transduction pathway in parallel to changes in auxin-related responses during nodule initiation, possibly via an increase in the production of flavonoids (Mathesius et al. 2000; Schultze and Kondorosi 1998). It will be important to integrate any potential role for flavonoids in a model of nodule and giant cell formation.

Previously, we showed that expression of Le-phan (tomato $P H A N$ ) is coincidental to that of $K N O X$, implying that prior models in which PHAN was postulated to a repressor of $K N O X$ were probably not an accurate description of events in tomato
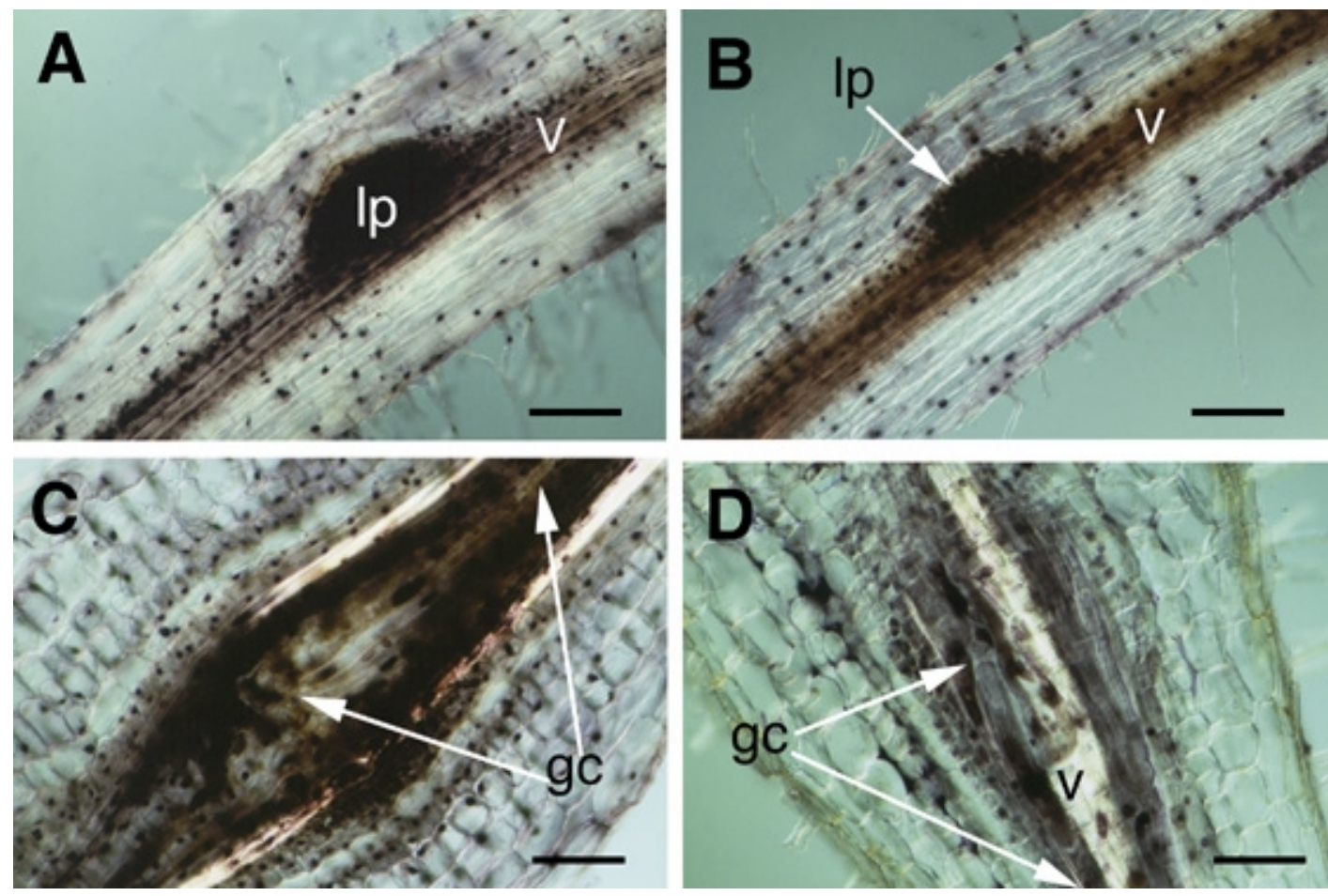

Fig. 4. In situ localization of Mt-ENOD40 and Mt-ccs52 transcripts in lateral roots and nematode-induced giant cells in Medicago truncatula. A and B, Detection of $M t-E N O D 40$ and $M t-c c s 52$ mRNAs, respectively, in longitudinal sections of roots at the site of lateral root primordia (lp). Dark staining represent detection of Mt-ENOD40 and Mt-ccs52 transcripts. v, vascular cylinder. C and D, Detection of Mt-ENOD40 and Mt-ccs52 mRNAs, respectively, in longitudinal sections of Medicago roots 6 days postinfection, with Meloidogyne incognita. Staining is apparent both in the nematode-induced giant cells (gc) and also in adjacent cells in the vascular cylinder. The ends of individual giant cells are delineated by arrows. Bars $=100 \mu \mathrm{m}$. 
(Koltai and Bird 2000a). Our finding of coincidental expression of Mt-phan and Mt-knox-1 in M. truncatula suggests the same is true for this compound-leaf plant as well. The coincidental expression of Mt-phan and Mt-knox-1 in lateral root primodia further implicates a general role for these genes in maintenance of a general meristematic state. Alternatively, it may implicate a broader role in the establishment of cell fate. We recently demonstrated that PHAN is epistatic to KNOX (J. Schaff, H. Koltai, and D. M. Bird, unpublished data). Furthermore, transgenic ablation of PHAN prevented establishment of normal giant cells (J. Schaff, H. Koltai, and D. M. Bird, unpublished data). Although not formally determined in Medicago, we suspect that Mt-phan may be epistatic to Mt-knox-1 in a signal transduction pathway active during normal plant development, nematode infection, and establishment of nitrogen-fixing nodules.

Rhizobial and root-knot nematode endosymbioses both involve formation of "giant," polyploid cells, although only the nematode-induced giant cells also are multinucleate. Differentiation of nodules is regulated by $\operatorname{ccs} 52$, which is highly expressed in differentiating nodule cells that undergo division arrest, followed by several rounds of endoreduplication and increase in cell size. The $\operatorname{css} 52$ protein is a substrate-specific activator of the anaphase-promoting complex and thus controls progression through mitosis (Cebolla et al. 1999). It is, therefore, highly significant that we detected expression of $\operatorname{ccs} 52$ in giant cells, as this suggests involvement of this mitotic inhibitor in the establishment of the multinucleated polyploid giant cell. The expression of $\operatorname{ccs} 52$ in lateral root meristems and in nodule primordia is somewhat surprising, since in the primary root meristem and differentiated nodules, it is expressed mainly in cells undergoing differentiation (Cebolla al. 1999). Perhaps there is a special need for $\operatorname{ccs} 52$ mitotic inhibition during the emergence of early stages of lateral root meristems and nodules. Alternatively, it may suggest a broader deployment for ccs52 in the establishment of cell fate in the plant. Expression of $\operatorname{css} 52$ both in giant cells and differentiating nodules reinforces the ontogenic similarities of these structures.

Expression of ENOD40 is induced by elevated cytokinin levels and/or inhibition of auxin (Fang and Hirsch 1998; Hirsch et al. 1989; Mathesius et al. 2000; van Rhijn et al. 1997; Wu et al. 1996). That, along with the similarity in the expression pattern of ENOD40 (Asad et al. 1994; Crespi et al. 1994; Fang and Hirsch 1998; Kouchi and Hata 1993) and KNOX in nodules at various stages of development and in nematode feeding sites and lateral root primordia, may suggest that ENOD 40 is a component in the $P H A N / K N O X$ signal transduction pathway. In nodules, ENOD40 is one element involved in controlling nodulation initiation and stimulation of cortical divisions, and its expression in giant cells and in developing gall tissues may suggest its involvement in cell proliferation as a plant response to nematode infection.

It is clearly evident from our work that the host response to both rhizobia and root-knot nematodes involves activation of a signal transduction pathway(s) also involved in normal meristem function. Although discussion of the origin of this commonality is obviously quite speculative, some alternatives can be formally proposed. One possibility is that constraints made by the biology of the host might dictate a common or overlapping response pathway. In other words, there may be no alter- native to exploiting the PHAN/KNOX pathway and $\operatorname{ccs} 52$ and ENOD40 to produce giant cells and nodules. This certainly might be true if indeed these pathways define a link between phytohormones and cellular responses. A different possibility is that the induction of common host function by root-knot nematodes and rhizobia might be indicative of some common element shared by these endosymbionts, and indeed, a role for a Nod factorlike molecule in the induction of giant cells has previously been proposed (Bird 1996). It seems highly unlikely that such an element could have originated from divergent evolution of a common nematode/bacterial ancestor, but it might be the result of independent, convergent evolution. An intriguing (but highly conjectural) possibility is that rhizobia and root-knot nematodes have exchanged genetic information via horizontal gene transfer, a process that has previously been documented in nematodes (Keen and Roberts 1998). EST sequencing (McCarter et al. 2000a, 2000b; D. M. Bird, unpublished data) recently revealed a nodL homologue in Meloidogyne incognita. The bacterial homologue of this enzyme is required for O-acetylation of Nod factor (Ardourel et al. 1994). Although there is no direct evidence that nematodes can produce Nod factor, it is well established that nematodes can synthesize the chitin core of Nod factor (Bird and Self 1995). Interestingly, what is perhaps the best-characterized gene known to be expressed in giant cells, viz., Tob-RB7 (Opperman et al. 1994), encodes the likely orthologue of soybean Nod26 (Yamamoto et al. 1990). Perhaps induction of nodules and giant cells is mechanistically more similar than we had previously imagined.

\section{MATERIALS AND METHODS}

\section{Plant growth and nematode and rhizobium inoculation.}

Seeds of M. truncatula (genotype W66100) were scarified for $10 \mathrm{~min}$ in concentrated $\mathrm{H}_{2} \mathrm{SO}_{4}$, washed several times with water, and disinfected by treating with Clorox for $2 \mathrm{~min}$. Disinfected seeds were imbibed overnight in water, decanted, and stored for a day to promote germination prior to transplantation either to soil or peat mix. Plants were maintained in the greenhouse and infected with nematodes or bacteria when 1 to 2 months old. Root-knot nematodes (Meloidogyne incognita) were maintained on tomato plants, egg masses extracted with $0.5 \% \mathrm{NaOCl}$, and second-stage larvae hatched as described by Hussey and Barker (1973). Each M. truncatula plant was infected with 1,000 larvae. S. meliloti type 3D0a2 (strain ATCC 9930) was obtained from the USDA/ARS Beltsville Rhizobium Culture Collection, and plants were inoculated as described by Somasegaran (1994).

\section{Isolation of M. truncatula PHANTASTICA and KNOX genes.}

Total RNA was extracted from $M$. truncatula young leaves and meristems, and cDNA was synthesized from an oligodeoxyribosylthymine primer and used as template for PCR. Primers were designed based on conserved sequences of PHANTASTICA and class I KNOX genes from various plant species. Amplification products were sequenced, and genespecific primers were designed to isolate the $3^{\prime}$ and $5^{\prime}$ ends of each Medicago gene. The $3^{\prime}$ end of each gene was amplified using gene-specific primers and an anchor primer $\left(5^{\prime}\right.$ ACTCTTGGGCCTGTGTGGCCT $_{(18)} 3^{\prime}$ ). To isolate the $5^{\prime}$ end, a poly-dC tail was added to the Medicago cDNA using 
terminal-deoxynucleotidyl-transferase (Boehringer Mannheim/ Hoffmann-La Roche, Basel, Switzerland), followed by PCR amplification using gene-specific primers and an anchor primer ( $5^{\prime}$ TTTGGCCACGCGTCGACTAGTACGGGGIGGGIIGGGIIG 3'). Amplification products were purified and cloned into pGEMT Easy vector (Promega, Madison, WI, U.S.A.), and the inserts were sequenced. Sequences corresponding to the mature transcripts of the M. truncatula PHANTASTICA (Mt-phan) and Tkn2 KNOX genes (Mt-knox1) were submitted to GenBank with the following accession numbers: AF308453 and AF308454, respectively. Multiple sequence alignments were performed using the PILEUP program (Genetics Computer Group, Inc., Madison, WI, U.S.A.).

\section{In situ primers and confirmation of gene specificity.}

Gene-specific primer pairs were designed to amplify transcribed portions of Mt-phan (5' CGTCTAGTCATTAGCCTTCAAGC $3^{\prime}$ and 5' GATGGTCTCTCTTTCACTAGTTT 3') and $M t$-knox-1 (5' CTTATCAAGTATGAGCAAGAACT $3^{\prime}$ and $5^{\prime}$ CCTAAGTATCCACTGTATTTTCT $3^{\prime}$ ). Based on sequences in GenBank, primer pairs were designed to amplify transcribed portions of the $M$. truncatula genes ccs52 (accession no. AF134835: 5' GGAACCGGTAATCGAAATCCACC $3^{\prime}$ and $5^{\prime}$ ACCAACAGAACAAACACAATCAT $3^{\prime}$ ) and ENOD-40 (accession no. X80262: 5' GGAGCCCTTTAAGCATCCTCTAA $3^{\prime}$ and 5' GAGTGATTGATACATAGCCATTA $\left.3^{\prime}\right)$. The specificity of each primer pair was established by amplification from M. truncatula genomic DNA of a predicted, unique fragment, the identity of which was confirmed by DNA sequencing.

In order to confirm the specificity of the staining obtained on nodule sections, postlocalization validation analyses $(\mathrm{H}$. Koltai and D. Bird, unpublished data) were performed. Briefly, supernatant was recovered from wells in which in situs were performed, and the digoxigenin (DIG)-labeled DNA was analyzed by agarose gel electrophoresis and specific detection of DIG, following transfer to a membrane. DIG-labeled DNA also was subjected to direct sequencing.

\section{In situ RT-PCR localization.}

Detection of gene-specific transcripts in tissue sections was performed by in-well in situ RT-PCR (Koltai and Bird 2000a). Briefly, M. truncatula meristems and roots (mock-inoculated or inoculated with Meloidogyne incognita or S. meliloti) were fixed in FAA $(63 \%$ ethanol, 5\% acetic acid, $2 \%$ formalin; $\mathrm{vol} / \mathrm{vol} / \mathrm{vol}$ ) and embedded in low-melting-point agarose. Sections $(50$ to $75 \mu \mathrm{m})$ were cut with a Vibratome microtome (Series 1000 Sectioning System, Technical Products International, O'Fallon, MO, U.S.A.) and individually transferred to a well of a thin-wall polycarbonate 96 well plate (Costar, Cambridge, MA, U.S.A.). Sections were subjected to RT followed by PCR amplification using gene-specific primers and DIG-11-dUTP (Boehringer Mannheim/Hoffmann-La Roche). Following washing and blocking, anti-DIG alkaline phosphatase-conjugated monoclonal antibody (Boehringer Mannheim/Hoffmann-La Roche) was added to the microtiter wells to detect the DIGlabeled PCR products. Sections were then gently removed from each well and stretched on microscope slides (MJ Research, Waltham, MA, U.S.A.) in a $50-\mu$ drop of $300 \mu \mathrm{g}$ of nitroblue tetrazolium per $\mathrm{ml}$ and $183 \mu \mathrm{g}$ of 5-bromo-4-chloro3-indolylphosphate toluidinium per ml. Development of the purple color was monitored by microscopy and stopped by rinsing sections with ultra pure water. To facilitate comparison of spatial patterns of expression of different genes within a particular tissue or organ, adjacent sections were, where feasible, book-matched so that the shared cut surface of adjacent sections could be challenged with different primers. Sections were observed and photographed on Kodachrome 64T film (Eastman Kodak, Inc., Rochester, NY, U.S.A.) using a Zeiss Axiophot microscope (Carl Zeiss, Oberkochen, Germany) equipped with Nomarski Differential Interference Contrast optics.

\section{ACKNOWLEDGMENTS}

We thank J. Schaff for her intellectual and experimental contributions to this project and N. E. Wilmoth for technical assistance. This work was supported by USDA-NRI award 99-35302-8233 and NSF Plant Genome award DBI0077503 to D. Bird and by a postdoctoral award no. FI-27098 from BARD, the United States-Israel Binational Agricultural Research and Development Fund, to H. Koltai.

\section{LITERATURE CITED}

Ardourel, M., Demont, N., Debellé, F. D., Maillet, F., de Billy, F., Promé, J. C., Dénarié, J., and Truchet, G. 1994. Rhizobium meliloti lipooligosaccharide nodulation factors: Different structural requirements for bacterial entry into target root hair cells and induction of plant symbiotic developmental responses. Plant Cell 6:1357-1374.

Asad, S., Fang, Y., Wycoff, K. L., and Hirsch, A. N. 1994. Isolation and characterization of cDNA and genomic clones of MsENOD40: Transcripts are detected in meristematic cells of alfalfa. Protoplasma 183: 10-23.

Bird, A. F. 1975. Symbiotic relationships between nematodes and plants. Pages 351-371 in: Symposia of the Society for Experimental Biology XXIX. Cambridge University Press, Cambridge.

Bird, A. F., and Self, P. G. 1995. Chitin in Meloidogyne javanica. Fundam. Appl. Nematol. 18:235-239.

Bird, D. M. 1996. Manipulation of host gene expression by root-knot nematodes. J. Parasitol. 82:881-888.

Bird, D. M., and Koltai, H. 2000. Plant parasitic nematodes: Habitats, hormones and horizontally-acquired genes. J. Plant Growth Reg. 19:183-194.

Bird, D. M., and Wilson, M. A. 1994. DNA sequence and expression analysis of root-knot nematode elicited giant cell transcripts. Mol. Plant-Microbe Interact. 7:419-424.

Cebolla, A., Vinardell, J. M., Kiss, E., Olah, B., Roudier, F., Kondorosi, A., and Kondorosi, E. 1999. The mitotic inhibitor ccs52 is required for endoreduplication and ploidy-dependent cell enlargement in plants. EMBO (Eur. Mol. Biol. Organ.) J. 18:4476-4484.

Charon, C., Sousa, C., Crespi, M., and Kondorosi, A. 1999. Alteration of enod40 expression modifies Medicago truncatula root nodule development induced by Sinorhizobium meliloti. Plant Cell 11:1953-1965.

Chen, J.-J., Janssen, B.-J., Williams, A., and Sinha, N. 1997. A gene fusion at a homeobox locus: Alteration in leaf shape and implication for morphological evolution. Plant Cell 9:1289-1304.

Cook, D. R. 1999. Medicago truncatula-A model in the making! Curr. Opin. Plant Biol. 2:301-304.

Crespi, M., and Gálvez, S. 2000. Molecular mechanisms in root nodule development. J. Plant Growth Reg. 19:155-166.

Crespi, M. D., Jurkevitch, E., Poiret, M., d'Aubenton-Carafa, Y., Petrovics, G., Kondorosi, E., and Kondorosi, A. 1994. enod40, a gene expressed during nodule organogenesis, codes for a non-translatable RNA involved in plant growth. EMBO (Eur. Mol. Biol. Organ.) J. 13:5099-5112.

Dénarié, J., Debellé, F., and Promé, J. C. 1996. Rhizobium lipo-chitooligosaccharide nodulation factors: Signaling molecules mediating recognition and morphogenesis. Annu. Rev. Biochem. 65:503-535.

Fang, Y., and Hirsch, A. M. 1998. Studying early nodulin gene ENOD40 expression and induction by nodulation factor and cytokinin in transgenic alfalfa. Plant Physiol. 116:53-68. 
Frugis, G., Giannino, D., Mele, G., Nicolodi, C., Innocenti, A. M., Chiappetta, A., Bitonti, M. B., Dewitte, W., Van Onckelen, H., and Mariotti, D. 1999. Are homeobox Knotted-like genes and cytokinins the leaf architects? Plant Physiol. 119:371-373.

Goliber, T., Kessler, S., Chen, J.-J., Bharathan, G., and Sinha, N. 1999. Genetic, molecular and morphological analysis of compound leaf development. Curr. Top. Dev. Biol. 43:259-290.

Hareven, D., Gutfinger, T., Parnis, A., Eshed, Y., and Lifschitz, E. 1996. The making of a compound leaf: Genetic manipulation of leaf architecture in tomato. Cell 84:735-744.

Hirsch, A. M., Bhuvaneswari, T. V., Torrey, J. G., and Bisseling, T. 1989. Early nodulin genes are induced in alfalfa root outgrowths elicited by auxin transport inhibitors. Proc. Natl. Acad. Sci. U.S.A. 86:12441248 .

Huang, C. S. 1985. Formation, anatomy and physiology of giant cells induced by root-knot nematodes. Pages 155-164 in: An Advanced Treatise on Meloidogyne, Vol. I. J. N. Sasser and C. C. Carter, eds. NCSU Graphics, Raleigh, NC, U.S.A.

Hussey, R. S., and Barker, K. R. 1973. A comparison of methods of collecting inocula of Meloidogyne spp., including a new technique. Plant Dis. Rep. 57:1025-1028.

Hutangura, P., Mathesius, U., Jones, M. G. K., and Rolfe, B. G. 1999. Auxin induction is a trigger for root gall formation caused by rootknot nematodes in white clover and is associated with the activation of the flavonoid pathway. Aust. J. Plant Physiol. 26:221-231.

Janssen, B.-J., Lund, L., and Sinha, N. 1998a. Overexpression of a homeobox gene, Let6, reveals indeterminate features in the tomato compound leaf. Plant Physiol. 117:771-786.

Janssen, B.-J., Williams, A., Chen, J.-J., Mathern, J., Hake, S., and Sinha, N. 1998b. Isolation and characterization of two knotted-like homeobox genes from tomato. Plant Mol. Biol. 36:417-425.

Keen, N. T., and Roberts, P. A. 1998. Plant parasitic nematodes: Digesting a page from the microbe book. Proc. Natl. Acad. Sci. U.S.A. 95: 4789-4790.

Koltai, H., and Bird, D. M. 2000a. Epistatic repression of PHANTASTICA and class 1 KNOTTED genes is uncoupled in tomato. Plant J. 22:455-459.

Koltai, H., and Bird, D. M. 2000b. High throughput cellular localization of specific plant mRNAs by liquid-phase in situ reverse transcriptionpolymerase chain reaction of tissue sections. Plant Physiol. 123:12031212

Kouchi, H., and Hata, S. 1993. Isolation and characterization of novel nodulin cDNAs representing genes expressed at early stages of soybean nodule development. Mol. Gen. Genet. 238:106-119.

Lerouge, P., Roche, P., Faucher, C., Maillet, F., Truchet, G., Promé, J. C., and Dénarié, J. 1990. Symbiotic host specificity of Rhizobium meliloti is determined by a sulphated and acylated glucosamine oligosaccharide. Nature 344:781-784.

Long, J. A., Moan, E. I., Medford, J. I., and Barton, M. K. 1996. A member of the KNOTTED class of homeodomain proteins encoded by the STM gene of Arabidopsis. Nature 379:66-69.

Mathesius, U., Schlaman, H. R. M., Spaink, H. P., Sautter, C., Rolfe, B., and Djordjevic, M. A. 1998. Auxin transport inhibition precedes root nodule formation in white clover roots and is regulated by flavanoids and derivatives of chitin oligosaccharides. Plant J. 14:23-34.

Mathesius, U., Charon, C., Rolfe, B. G., Kondorosi, A., and Crespi, M. 2000. Temporal and spatial order of events during the induction of cortical cell divisions in white clover by Rhizobium leguminosarum bv. trifolii inoculation or localized cytokinin addition. Mol. PlantMicrobe Interact. 13:617-628.

McCarter, J., Bird, D. M., Rao, U., Kloek, A., Clifton, S., Pape, D., Martin, J., Wylie, T., Eddy, S., Waterston, R., and the Washington University GSC EST Team. 2000a. Progress toward high throughput gene discovery in parasitic nematodes: Initial findings from Meloidogyne incognita EST sequencing. J. Nematol. 32:445.

McCarter, J. P., Bird, D. M., Clifton, S. W., and Waterston, R. H. 2000b. Nematode gene sequences; Update for December 2000. J. Nematol. 32:331-333.
Opperman, C. H., Taylor, C. G., and Conkling, M. A. 1994. Root-knot nematode-directed expression of a plant root-specific gene. Science 263:221-223.

Parnis, A., Cohen, O., Gutfinger, T., Hareven, D., Zamir, D., and Lifschitz, E. 1997. The dominant developmental mutant of tomato, mouse-ear and curl, are associated with distinct modes of abnormal transcriptional regulation of a knotted gene. Plant Cell 9:2143-2158.

Parniske, M. 2000. Intracellular accommodation of microbes by plants: A common developmental program for symbiosis and disease? Curr Opin. Plant Biol. 3:320-328.

Pelosi, A., Lee, M. C. S., Chandler, S. F., and Hamill, J. D. 1995. Hormonal control of root primordia differentiation and root formation in cultured explants of Eucalyptus globulus seedlings. Aust. J. Plant Physiol. 22:409-415.

Rupp, H. M., Frank, M., Werner, T., Strnad, M., and Schmulling, T. 1999. Increased steady state mRNA levels of the STM and KNAT1 homeobox genes in cytokinin overproducing Arabidopsis thaliana indicate a role for cytokinins in the shoot apical meristem. Plant J. 18: 557-563.

Sakamoto, T., Nishimura, A., Tamaoki, M., Kuba, M., Tanaka, H., Iwahori, S., and Matsuoka, M. 1999. The conserved KNOX domain mediates specificity of tobacco KNOTTED1-type homeodomain proteins. Plant Cell 11:1419-1432.

Schneeberger, R., Tsiantis, M., Freeling, M., and Langdale, J. A. 1998. The rough sheath 2 gene negatively regulates homeobox gene expression during maize leaf development. Development 125:2857-2865.

Schultze, M., and Kondorosi, A. 1998. Regulation of symbiotic root nodule development. Annu. Rev. Genet. 32:33-57.

Somasegaran, P. 1994. Handbook for Rhizobia: Methods in LegumeRhizobium Technology. P. Somasegaran and H. J. Hoben, eds. Springer-Verlag, New York.

Thiery, M. G., Greene, A. E., and Bird, D. M. 1999. The Lycopersicon esculentum orthologue of PHANTASTICA/rough sheath2 (accession no. AF148934) is expressed in feeding sites induced by root-knot nematodes. Plant Physiol. 120:934.

Timmermans, M. C. P., Hudson, A., Becraft, P. W., and Nelson, T. 1999. ROUGH SHEATH2: A Myb protein that represses knox homeobox gene in maize lateral organ primordia. Science 284:151-153.

Truchet, G., Roche, P., Lerouge, P., Vasse, J., Camut., S., de Billy, F., Promé, J. C., and Dénarié, J. 1991. Sulphated lipo-oligosaccharide signals of Rhizobium meliloti elicit root nodule organogenesis in alfalfa. Nature 351:670-673.

Tsiantis, M., Brown, M. I. N., Skibinski, G., and Langdale, J. A. 1999a. Disruption of auxin transport is associated with aberrant leaf development in maize. Plant Physiol. 121:1163-1168.

Tsiantis, M., Schneeberger, R., Golz, J. F., Freeling, M., and Langdale, J. A. $1999 \mathrm{~b}$. The maize rough sheath 2 gene and leaf development programs in monocot and dicot plants. Science 284:154-156.

van Rhijn, P., Fang, Y., Galili, S., Shaul, O., Atzmon, N., Wininger, S., Eshed, Y., Lum, M., Li, Y., To, V., Fujishge, N., Kapulnik, Y., and Hirsch, S. M. 1997. Expression of early nodulin genes in alfalfa mycorrhizae indicates that signal transduction pathways used in forming arbuscular mycorrhizae and Rhizobium-induced nodules may be conserved. Proc. Natl. Acad. Sci. U.S.A. 94:5467-5472.

Waites, R., Selvandurai, H. R. N., Oliver, I. R., and Hudson, A. 1998. The PHANTASTICA gene encodes a MYB transcription factor involved in growth and dorsoventrality of lateral organs in Antirrhinum. Cell 93:779-789.

Williamson, V. M., and Hussey, R. S. 1996. Nematode pathogenesis and resistance in plants. Plant Cell 8:1735-1745.

Wu, C. F., Dickstein, R., Cary, A. J., and Norris, J. H. 1996. The auxin transport inhibitor N-(1-naphthyl)phthalamic acid elicits pseudonodules on nonnodulating mutants of white sweetclover. Plant Physiol. 110:501-510.

Yamamoto, Y., Cheng, C.-L., and Conkling, M. E. 1990. Root-specific genes from tobacco and Arabidopsis homologous to an evolutionarily conserved gene family of membrane channel proteins. Nucleic Acids Res. 18:7449. 